\title{
Evidence of Physical and Chemical Nonequilibrium in Lead and Cadmium Transport and Sorption in Acid Soils
}

\author{
F. Garrido, \\ S. Serrano \\ Instituto de Ciencias Agrarias \\ Centro de Ciencias Medioambientales \\ Consejo Superior de Investigaciones Científicas \\ Serrano 115 dpdo \\ 28006, Madrid \\ Spain
}

\section{G. Campbell}

Lawrence Livermore National Lab.

7000 East Ave.

L-627

Livermore, CA 94550

Now at:

Geosyntec Consutants

Oakland, CA 94612

\section{Barrios}

Centro Técnico de Informática

Consejo Superior de Investigaciones Científicas

Pinar 19

28006 Madrid

Spain

\section{T. García-González}

Instituto de Ciencias Agrarias

Centro de Ciencias Medioambientales

Consejo Superior de Investigaciones Científicas

Serrano 115 dpdo

28006, Madrid

Spain
Environmental issues regarding soil trace metals often center on mobility and bioavailability. Transport of metals through the soil system could be affected by physical or chemical nonequilibrium processes. In this study, the physiochemical factors involved in $\mathrm{Pb}$ and $\mathrm{Cd}$ transport and sorption in soils were examined to determine the fate of metal pollutants. A series of metal miscible displacement experiments were executed following a full factorial statistical design including five sources of variability: soil ( $\mathrm{S} 1$ and $\mathrm{S} 2)$, metal ( $\mathrm{Pb}$ and $\mathrm{Cd}$ ), metal initial concentration $\left(C_{0}\right)$, water flux rate $\left(J_{\mathrm{w}}\right)$, and depth $(0-4$ and $4-8 \mathrm{~cm})$. Temporal moment analysis of the measured breakthrough curves (BTCs) revealed that $\mathrm{Cd}$ transport is characterized by larger mass recovery values and lower estimated values of the transport timing-mean travel time $(\mu)$ and vertical solute spreading $\left(\sigma^{2}\right)$ - than $\mathrm{Pb}$. This indicates the high affinity and retention of $\mathrm{Pb}$ in the soil and the high mobility of $\mathrm{Cd}$. On the other hand, the sorption parameters for both $\mathrm{Pb}$ and $\mathrm{Cd}$ were estimated from a sequential chemical extraction of the metal retained in the soil column. The effect of the sources of variability on both transport and sorption parameters were determined. The functional relationship between sorption and transport parameters was also estimated through a linear regression and canonical correlation analysis. Physical and chemical nonequilibrium in transport processes were demonstrated by BTC tailing, changing BTC characteristics $\left(\mu\right.$ and $\left.\sigma^{2}\right)$ with $J_{\mathrm{w}}$ and $C_{0}$, and semi-irreversible sorption identified by sequential extraction.

Abbreviations: BTC, breakthrough curve; ICP-AES, inductively coupled plasma-atomic emission spectrometry.

Tndustrial discharges, fertilizer application, sewage and sludge 1 disposal, as well as mining activities have resulted in the deposition and accumulation of trace metals in soils (Förstner, 1995). For example, accidents such as the mining spill at Aznalcóllar

Soil Sci. Soc. Am. J. 72:1434-1444

doi:10.2136/sssaj2007.0411

Received 30 Nov. 2007.

*Corresponding author (fernando.garrido@ccma.csic.es).

(C) Soil Science Society of America

677 S. Segoe Rd. Madison WI 53711 USA

All rights reserved. No part of this periodical may be reproduced or transmitted in any form or by any means, electronic or mechanical, including photocopying, recording, or any information storage and retrieval system, without permission in writing from the publisher. Permission for printing and for reprinting the material contained herein has been obtained by the publisher. in Andalusia, southern Spain, in April 1998 continue to occur and degrade large areas of agricultural soils (Aguilar et al., 2004). Metal contaminants either accumulate in soils or leach and percolate into local groundwater, polluting aquifers and potential drinking water supplies. Among these metal contaminants, two of the most toxic are $\mathrm{Cd}$ and $\mathrm{Pb}$. Classified as soluble and strongly hydrating cations (McBride, 1994), both metals are particularly toxic to higher animals, producing kidney and blood diseases among other health disorders (Adriano, 2001).

Environmental issues regarding soil trace metals often center on mobility and bioavailability. Transport of metals in groundwater systems could be affected by physical nonequilibrium processes (e.g., soil heterogeneity, preferential flow, and kinetic diffusion) or chemical nonequilibrium processes (e.g., caused by kinetic sorption or ion exchange and hysteretic sorption) (Pang et al., 2002). Local equilibrium conditions are only 
Table 1. Physical, chemical, and mineralogical properties of the soils.

\begin{tabular}{|c|c|c|c|c|c|c|c|c|c|c|c|c|}
\hline Soil & $\mathrm{pH}_{\mathrm{w}}{ }^{\dagger}$ & $\mathrm{pH}_{\mathrm{k}} \neq$ & Organic C & $\mathrm{Ca}$ & Mg & $\mathrm{Na}$ & K & Al & ECEC§ & Sand & Silt & Clay \\
\hline & & & $\mathrm{g} \mathrm{kg}^{-1}$ & & 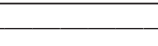 & $\mathrm{cmol}$ & ${ }_{\mathrm{c}} \mathrm{kg}^{-1}$ & & 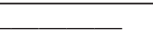 & & $-\mathrm{g} \mathrm{kg}^{-1}$ & \\
\hline S1 & $5.2(0.02)$ ฯ & $4.2(0.03)$ & $17(1.0)$ & $0.32(0.02)$ & $0.08(0.00)$ & $0.04(0.00)$ & $0.09(0.00)$ & $1.26(0.08)$ & $1.79(0.11)$ & $675(38)$ & $250(15)$ & $75(5)$ \\
\hline S2 & $5.0(0.02)$ & $3.8(0.01)$ & $3(0.1)$ & $0.06(0.00)$ & $0.20(0.02)$ & $0.02(0.00)$ & 0.11 & $0.7(0.03)$ & $1.09(0.05)$ & $710(42)$ & $245(16)$ & $45(6)$ \\
\hline
\end{tabular}

$\mathrm{t} \mathrm{pH}$ measured in deionized water.

$\neq \mathrm{pH}$ measured in $1 \mathrm{~mol} \mathrm{~L}^{-1} \mathrm{KCl}$.

$\S$ Effective capacity of the exchange complex.

I Mean values with standard deviations in parentheses $(n=3)$.

valid when solute transport occurs in a homogeneous porous medium and sorption is linear, reversible, and not kinetically limited. Therefore, most natural systems are rarely homogeneous and sorption is not established instantaneously during solute transport in soils (Brusseau et al., 1989; Kookana and Naidu, 1998). Consequently, the metal retention processes in the soil matrix should be studied under nonequilibrium conditions to correctly establish the risks associated with the presence of these elements in soils.

The complexity of the soil matrix, the simultaneous presence of contaminant elements in the soil solutions (resulting in competitive sorption), the variability of the geochemical conditions, and wide range of initial metal concentrations results in difficulty in determining sorption mechanisms under nonequilibrium conditions. An approach commonly used to study the mobility of metals in soils is a sequential chemical extraction procedure such as those developed by Tessier et al. (1979) and Shuman (1985). The accuracy and validity of these methods for the purpose of metal speciation has been questioned due to nonselectivity of the reagents in the sequential steps and to the possibility of metal readsorption during the extraction (Kim and McBride, 2006). Through the determination of the element distribution in the different soil solid fractions as a function of its chemical extractability, however, the availability of the element for transport and biological uptake may be inferred (Chlopecka and Adriano, 1996).

A complementary approach to examining transport processes is the application of temporal moment analysis to concentration breakthrough curves (BTCs) in contaminant transport studies (Valocchi, 1990; Campbell et al., 2006). This method may be used to estimate the transport parameters associated with a pollution element (Pang et al., 2003) and thus characterize its movement under different experimental conditions.

This study had three objectives designed to examine nonequilibrium heavy metal transport. The first was the study of the effect of the initial conditions including: soil type (S1 and $\mathrm{S} 2)$, metal $(\mathrm{Pb}$ and $\mathrm{Cd})$, initial metal concentration $\left(C_{0}\right)$, and water flux rate $\left(J_{\mathrm{w}}\right)$ on physical and chemical nonequilibrium transport. The second objective was to examine the depth distribution $(0-4$ and $4-8 \mathrm{~cm})$ and mobility in the $\mathrm{Pb}$ and $\mathrm{Cd}$ transport using a sequential metal extraction procedure. Finally, the third objective was to determine the functional relationship between sorption and transport parameters through linear regression and canonical correlation analysis.

₹ Trace.

$\S$ Not determined.

ฯ Not detected.

\section{MATERIALS AND METHODS Soil Characteristics and Sample Collection}

Two weathered acidic soils, developed from Pliocene-Quaternary aged formations in central Spain and classified as a Plinthic Palexerult (S1) and an Arenic Pachic Palexerult (S2) (Soil Survey Staff, 1999), were used for this study. Soil columns were collected from two level field sites. A total of 12 undisturbed columns of soil (8-cm diameter by $20-\mathrm{cm}$ length) were taken from the Ap horizon by pressing beveled polyvinyl chloride cylinders into the soil on a uniform grid at $50-\mathrm{cm}$ intervals. Once the cylinders were placed in the soil at the desired depth, the surrounding soil was carefully excavated and the columns were removed from the ground, capped, and transported to the laboratory. The moisture content (averaging a gravimetric water content of $0.20 \pm 0.01$ ) of the soil at the sampling time minimized compaction and disturbance. The columns were kept wet with deionized water until their subsequent use on trays filled with bulk soil. In addition, samples of the Ap horizon of each soil were collected at various locations surrounding the zone used for column extractions, air dried, crushed, sieved through a 2-mm mesh, and bulked before general characterization.

Selected physical, chemical, and mineralogical properties of the horizon are summarized in Tables 1 and 2. Soil $\mathrm{pH}$ was measured in deionized water $\left(\mathrm{pH}_{\mathrm{w}}\right)$ and in $1 \mathrm{~mol} \mathrm{~L}^{-1} \mathrm{KCl}\left(\mathrm{pH}_{\mathrm{K}}\right.$, in a $1: 2.5$ suspension), and organic $\mathrm{C}$ was determined by wet digestion (Walkley and Black, 1934). The exchangeable bases were extracted with $1 \mathrm{~mol}$ $\mathrm{L}^{-1} \mathrm{NH}_{4} \mathrm{OAc}\left(\mathrm{pH} 7\right.$; Thomas, 1982), and the exchangeable $\mathrm{Al}\left(\mathrm{Al}_{\mathrm{K}}\right)$ was determined with $1 \mathrm{~mol} \mathrm{~L}^{-1} \mathrm{KCl}$ (Barnhisel and Bertsch, 1982). The effective capacity of the exchange complex was calculated as the sum of $\mathrm{Al}_{\mathrm{K}}$ and the amounts of $\mathrm{Ca}, \mathrm{Mg}, \mathrm{Na}$, and $\mathrm{K}$ extracted by $1 \mathrm{~mol} \mathrm{~L}^{-1} \mathrm{NH}_{4} \mathrm{OAc}$ at $\mathrm{pH} 7$ (Shuman, 1990). The supernatants from each extraction were separated by centrifugation and stored in polyethylene containers at $4^{\circ} \mathrm{C}$ until analysis. Analyses were performed in triplicate. The $\mathrm{Ca}, \mathrm{Mg}, \mathrm{K}, \mathrm{Na}$, and $\mathrm{Al}$ contents were determined by inductively coupled plasma-atomic emission spectrometry (ICPAES) on a PerkinElmer OPTIMA 4300DV (PerkinElmer Corp.,

Table 2. Semiquantitative mineralogical compositiont of the soils.

\begin{tabular}{|c|c|c|c|c|c|c|c|c|c|c|c|}
\hline Soil & Fraction & $\mathbf{Q}$ & $\mathrm{F}_{\mathrm{Ca}-\mathrm{Na}}$ & $F_{K}$ & G & $\mathbf{H}$ & Ph & $\mathbf{S}$ & V & I & K \\
\hline & & & & & elative & o bet & en sa & les & 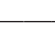 & & - \\
\hline \multirow{2}{*}{ S1 } & $\leq 2 \mathrm{~mm}$ & 74 & $\operatorname{tr} \neq$ & $\operatorname{tr}$ & 4 & 3 & 19 & $-\S$ & - & - & - \\
\hline & $\leq 2 \mu \mathrm{m}$ & 12 & ND & ND & 6 & 6 & 76 & ND & 8 & 11 & 57 \\
\hline \multirow{2}{*}{ S2 } & $\leq 2 \mathrm{~mm}$ & 52 & 8 & 31 & ND & ND & 9 & - & - & - & - \\
\hline & $\leq 2 \mu \mathrm{m}$ & 13 & 5 & 4 & ND & ND & 78 & ND & ND & 52 & 26 \\
\hline
\end{tabular}

$+\mathrm{Q}=$ quartz, $\mathrm{F}_{\mathrm{Ca}-\mathrm{Na}}=\mathrm{Ca}$ - and Na-rich feldspars, $\mathrm{F}_{\mathrm{K}}=\mathrm{K}$-rich feldspars, $\mathrm{G}=$ goethite, $\mathrm{H}=$ hematite, $\mathrm{Ph}=$ phyllosilicates, $\mathrm{V}=$ vermiculite, $\mathrm{S}=$ smectite, $\mathrm{I}=$ illite, $\mathrm{K}=$ kaolinite. 
Table 3. Initial metal concentration $\left(C_{0}\right)$ and water flux rate $\left(J_{w}\right)$ in the transport experiments.

\begin{tabular}{|c|c|c|c|c|}
\hline \multirow{2}{*}{ Parameter } & \multicolumn{2}{|c|}{ Soil S1 } & \multicolumn{2}{|c|}{ Soil S2 } \\
\hline & $\mathbf{P b}$ & Cd & $\mathbf{P b}$ & Cd \\
\hline High $\mathrm{C}_{0}, \mathrm{mg} \mathrm{L}^{-1}$ & 4950 & 3233 & 3600 & 2800 \\
\hline Low $\mathrm{C}_{0}, \mathrm{mg} \mathrm{L}^{-1}$ & 2300 & 1560 & 2900 & 1800 \\
\hline Fast $\mathrm{J}_{\mathrm{w}^{\prime}} \mathrm{cm} \mathrm{h}^{-1}$ & 0.81 & 0.81 & 0.81 & 0.81 \\
\hline Slow $J_{w^{\prime}} \mathrm{cm} \mathrm{h}^{-1}$ & 0.43 & 0.43 & 0.43 & 0.43 \\
\hline
\end{tabular}

Norwalk, CT). The mineralogical compositions of the total ( $\leq 2-\mathrm{mm})$ and clay $\leq 2-\mu \mathrm{m}$ ) fractions were identified by $\mathrm{x}$-ray powder diffraction on a Philips X'Pert diffractometer with graphite-monochromated $\mathrm{CuK} \alpha$ radiation (PANalytical, Amelo, the Netherlands). We obtained semiquantitative estimates of the minerals from random powder and oriented aggregate patterns.

For all metal concentration determinations performed by ICPAES, calibration curves for elemental analyses were run before and after each sample series (20 samples including matrix-matched blanks and in-between calibration checks). The calibration solutions covered the range of the concentrations in the samples and were prepared in the same matrix as the extracting reagents from certified stock solutions. Sample blanks were analyzed for correction of background effect on instrument response. Trace metal standards were used to assess instrument precision. We calculated metal concentrations in unknown solutions on the basis of the external calibration, averaging the concentrations from two repetitions for each experimental replication. The limits of detection were calculated as three standard deviations of the instrument response from 10 repeated analyses of sample matrixmatched blank solutions. The detection limits showed that a concentration of a few micrograms per liter of the two metals could be analyzed.

\section{Leaching Experiments Experimental Conditions}

All metal leaching experiments were performed following a full factorial statistical design, including four sources of variability, each one with two response values, and three replicates for each experimental case. These sources of variability were: soil, metal, metal initial concentration, and water flux rate. The values of the metal pulse initial concentration and water flux rate are shown in Table 3 .

\section{Miscible Displacement Studies}

All leaching experiments were done under unsaturated steadystate flow conditions (averaging a volumetric water content of 0.34 $\pm 0.02)$ and at room temperature $\left(24 \pm 2^{\circ} \mathrm{C}\right)$. The soil columns were initially eluted with $1 \mathrm{mmol} \mathrm{L}^{-1} \mathrm{CaCl}_{2}$ as the background solution from the top boundary of the column at the desired constant flow rate, ensured by using an adjustable-speed peristaltic pump. After steady-state water flow was achieved, a $400-\mathrm{mL}$ pulse of a $\mathrm{Pb}$ and $\mathrm{Cd}$ solution containing the concentrations of both metals indicated in Table 3 for each experimental case was applied to the surface of the columns using the same irrigation system. These metal concentrations were believed to be necessary to assure metal migration through the soil columns in a workable period of time to achieve breakthrough. All metal solutions were prepared from their $\mathrm{Cl}^{-}$salts in the background solution. Theoretical calculations by MINTEQA2 (Allison et al., 1991) indicated that the solutions were not saturated with respect to any $\mathrm{Cd}$ species at the $\mathrm{pH}$ of the solution; however, $\mathrm{Pb}$ was found to be saturated with respect to laurionite at a concentration $<0.29 \%$ in all metal solutions. Thus, all solutions were filtered before their use in the experiments to ensure the total solubilization of the metal species.

Immediately following the pulse of metals, leaching was resumed with the background solution displacing the pulse through the soil columns until the metal concentrations in the effluent were reduced to zero. In all experiments, an air gap was left between the background and metal solutions to prevent dispersion in the irrigation tubes. Samples of effluent were collected at regular time intervals with an automatic fraction collector and analyzed for $\mathrm{pH}$, electrical conductivity, $\mathrm{Cl}^{-}$(measured by an ion-selective electrode), and $\mathrm{Cd}, \mathrm{Pb}, \mathrm{Ca}$, and $\mathrm{Al}$ (by ICP-AES).

\section{Moment Analyses}

Temporal moment analysis is a method to quantitatively represent a statistical probability distribution (in this case the metal BTCs) using characteristic values (Valocchi, 1990). Calculation of these moments and details on the transfer function approach may be found in Jury and Roth (1990) and Valocchi (1990). The BTCs from all the soil columns were analyzed by calculating the first $(\mu)$ and second $\left(\sigma^{2}\right)$ temporal moments as the times corresponding to the statistical mean and variance of this distribution. The first temporal moment $(\mu)$ is defined as

$$
\mu=\int_{0}^{\infty} t f(t) \mathrm{d} t
$$

where $t$ is time on the $x$ axis of the BTC and $f(t)$ is the probability distributions of tracer travel times, also called the transfer function. This temporal moment characterizes the mean displacement time of the solute or mean travel time expressed in time units. The second temporal moment or variance $\left(\sigma^{2}\right)$ represents the spreading of the distribution along the $x$ axis expressed in units of time squared. This value is defined as

$$
\sigma^{2}=\int_{0}^{\infty}(t-\mu)^{2} f(t) \mathrm{d} t
$$

where $\mu$ is the first temporal moment and $t$ is again time on the $x$ axis (Mallants et al., 1994).

Additionally, mass recovery of the metal exiting each soil column was calculated using the BTCs. The tracer mass is commonly presented as the mass measured vs. the mass applied, or mass recovery $\left(M_{\mathrm{r}}\right)$, given by

$$
M_{\mathrm{r}}=\sum\left[\left(C_{(t)}^{\mathrm{f}} / C_{0}\right) V_{\mathrm{w}}(t)\right]
$$

where $C_{(t)} f_{/} C_{0}$ is the flux $(f)$ metal concentration exiting the soil columns measured in each sample divided by the initial concentration of the metal in the metal pulse added to the column; $V_{\mathrm{w}}(t)$ is the volume of water in each glass tube of the fraction collector for each sampling period. This value is therefore the total normalized metal mass per unit time exiting the soil column.

\section{Sequential Extraction Procedure, Metal Fractionation}

Following the end of miscible displacement studies, all columns were dismantled and the soil sectioned at approximately $4-\mathrm{cm}$ intervals. The portions obtained at 0 to 4 and 4 to $8 \mathrm{~cm}$ from the surface (discarding the first $0.5 \mathrm{~cm}$ from the surface) were air dried, crushed, and sieved through a $2-\mathrm{mm}$ mesh for subsequent analysis of metal in the solid phase. Duplicate 10-g subsamples from each soil portion and column (considered pseudo-replicates) were used to fraction the metals in the solid phase into the following operational fractions according to the method proposed by Shuman (1985): 
1. Exchangeable metal fraction extracted with $1 \mathrm{~mol} \mathrm{~L}^{-1} \mathrm{Mg}\left(\mathrm{NO}_{3}\right)_{2}$ at $\mathrm{pH} 7\left(F^{\mathrm{I}}\right)$

2. Metal bound to organic matter extracted with $0.7 \mathrm{~mol} \mathrm{~L}^{-1} \mathrm{NaOCl}$ at $\mathrm{pH} 8.5\left(F^{\mathrm{II}}\right)$

3. Metal fraction bound to $\mathrm{Mn}$ oxides extracted with $0.1 \mathrm{~mol} \mathrm{~L}^{-1} \mathrm{NH}_{2} \mathrm{OH} \times \mathrm{HCl}$ at $\mathrm{pH} 2\left(F^{\mathrm{III}}\right)$

4. Metal fraction bound to amorphous $\mathrm{Fe}$ oxides extracted with $0.2 \mathrm{~mol} \mathrm{~L}^{-1}\left(\mathrm{NH}_{4}\right)_{2} \mathrm{C}_{2} \mathrm{O}_{4} \times \mathrm{H}_{2} \mathrm{O}+0.2 \mathrm{~mol} \mathrm{~L}^{-1} \mathrm{H}_{2} \mathrm{C}_{2} \mathrm{O}_{4}$ at $\mathrm{pH} 3\left(F^{\mathrm{IV}}\right)$

5. Metal fraction bound to crystalline Fe oxides following an extraction procedure similar to that for Step 4 plus an additional extraction with $0.1 \mathrm{~mol} \mathrm{~L}^{-1}$ ascorbic acid $\left(F^{\mathrm{V}}\right)$

In addition, we determined the total metal content $\left(F^{\text {Tot }}\right)$ in duplicate subsamples (pseudo-replicates) by digestion in aqua regia $\left(3: 1 \mathrm{v} / \mathrm{v} 12 \mathrm{~mol} \mathrm{~L}^{-1} \mathrm{HCl} / 14 \mathrm{~mol} \mathrm{~L}^{-1} \mathrm{HNO}_{3}\right.$ ) as described by Vercoutere et al. (1995). All metal concentration values obtained for each extraction step (fractions) mentioned above were converted into percentages with respect to the total metal content. All extracts and digests were stored in polyethylene tubes at $4^{\circ} \mathrm{C}$ for analysis and metal concentrations were determined by ICP-AES. We followed the same quality control system as described above.

\section{Statistical Analysis \\ Statistical Design}

The effect of the above-mentioned variability factors (except depth) on the characteristic metal transport parameters $\left(M_{\mathrm{r}}, \mu\right.$, and $\left.\sigma^{2}\right)$ was studied based on a $2^{n}(n=4)$ experimental design with two response levels $(i=2)$ for each variability factor (soil, metal, $J_{\mathrm{w}}$, and $\left.C_{0}\right)$ and three replicates $(j=3)$. This way, for each combination of three variability factors, the differences found in the transport parameters were contrasted by means of one-way ANOVA. On the other hand, to study the effect of soil (S1 and S2), metal (Pb and Cd), metal initial concentration $\left(C_{0}\right)$, water flux rate $\left(J_{\mathrm{w}}\right)$ on the sorption patterns as described by the group of fractions obtained from the sequential extraction procedure $\left\{k=5 ; F^{\mathrm{I}}, F^{\mathrm{II}}, F^{\mathrm{III}}, F^{\mathrm{IV}}, F^{\mathrm{V}}\right\}$ and total metal content $\left\{F^{\text {Tot }}\right\}$, the same statistical model was applied, this time considering the nested effect of the depth factor with two measurement levels: 0 to 4 and 4 to $8 \mathrm{~cm}$. Thus, given the sources of variability considered ( $n=5$; soil, metal, depth, $J_{\mathrm{w}}$, and $C_{0}$ ) with two response levels $(i=2)$ and three replicates $(j=3$; obtained from the mean of the corresponding pseudo-replicates after verifying the absence of statistical differences among them), for each combination of four variability factors, the differences in each of the $k$ fractions $(k=5)$ as a result of the fifth variability factor were studied by means of an one-way ANOVA including the fraction $(k-1)$ as a covariable. Both ANOVA procedures were performed using the statistical program SPSS Version 14.0 (SPSS Inc., Chicago, IL).

\section{Functional Relationships between Sorption and Transport Parameters}

Linear Regression Analysis. Given both transport $\left\{\mu, \sigma^{2}, M_{\mathrm{r}}\right\}$ and sorption $\left\{F^{\mathrm{I}}, F^{\mathrm{II}}, F^{\mathrm{III}}, F^{\mathrm{IV}}, F^{\mathrm{V}}\right\}$ parameters, the best combination of sorption parameters to explain each transport parameter was sequentially selected by means of a stepwise multiple linear regression analysis. This procedure was done for the all the possible combinations of soil $\times$ metal, not taking into account the existing differences in the values of sorption parameters produced by the other three variability factors considered in this study $\left(J_{\mathrm{w}}, C_{0}\right.$, and depth). These analyses were done using the statistical program SPSS Version14.0.
Canonical Correlation Analysis. Last, a canonical correlation analysis was performed for studying the linear relationships between transport and sorption parameters without considering any sort of dependency between them. By means of this procedure, the Pearson correlation coefficient matrix of transport and sorption parameters was interpreted for each metal, evaluating the maximum global multivariate relationship between both groups of parameters. These analyses were done using the statistical program SAS 8.2 in Windows XP (SAS Institute, Cary, NC).

\section{RESULTS AND DISCUSSION Initial Conditions and Transport Patterns}

The mean BTCs for Pb and Cd (calculated from the three replicated BTCs) obtained for the different experimental conditions are shown in Fig. 1 and the corresponding estimated mean values of the transport parameters are shown in Fig. 2. The Cd transport pattern observed in both soils is characterized by larger mass recoveries and lower first and second temporal moments $\left(\mu\right.$ and $\sigma^{2}$ ) than observed in the $\mathrm{Pb}$ transport. This different behavior is illustrated by significant differences (data not shown) between the mean transport parameters values estimated for each metal in most of the experiments performed in this study. The explanation for the observed differences in transport lies in the greater mobility of $\mathrm{Cd}$ compared with $\mathrm{Pb}$ (Camobreco et al., 1996; Voegelin et al., 2003) and the greater tendency of $\mathrm{Pb}$ to be strongly retained in the soil matrix through the formation of inner sphere complexes (Papelis and Hayes, 1996; Chen and Hayes, 1999; Strawn and Sparks, 1999). Contrary to $\mathrm{Pb}, \mathrm{Cd}$ has been demonstrated to have a lower tendency to hydrolyze, tends to form outer sphere complexes on exchange positions of the mineral surfaces (Bradbury and Baeyens, 2005), and thus is more readily displaced to the soil solution (Hooda and Alloway, 1998; Voegelin et al., 2003). This different sorption behavior leads to longer residence times for Pb than for Cd (Pang et al., 2002).

The soil type did not produce remarkable differences between the transport patterns of each metal although, in general, greater mass recovery values and shorter mean travel times were estimated for both metals in Soil S2 than in S1, probably as a result of the coarser texture of S2 (Table 1) and greater sorption capacity of S1 (Serrano et al., 2005); however, these differences were more noticeable for the case of $\mathrm{Pb}$ than $\mathrm{Cd}$. For instance, at rapid water flux $\left(J_{\mathrm{w}}^{\text {fast }}\right)$ and high initial metal concentration $\left(C_{0}^{\text {high }}\right)$, the estimated $\mathrm{Pb}$ mean values of $M_{\mathrm{r}}$ and $\mu$ were $8 \pm 2 \%$ and $62 \pm 14 \mathrm{~h}^{-1}$, respectively, for Soil S1, while for Soil S2, these values were $22 \pm 8 \%$ and $25 \pm 2 \mathrm{~h}^{-1}$, respectively. Under the same experimental conditions, $\mathrm{Cd} M_{\mathrm{r}}$ and $\mu$ values varied from $72 \pm 2 \%$ and $19 \pm 1 \mathrm{~h}^{-1}$, respectively, in Soil S1 to $89 \pm 1 \%$ and $23 \pm 2 \mathrm{~h}^{-1}$, respectively, in Soil S2. This different effect of the soil properties on the metal transport patterns might be explained by the greater affinity for $\mathrm{Pb}$ of Fe oxides and the greater Fe oxide content in the clay fraction of Soil S1 than Soil S2 (Table 2); however, Cd also shows affinity for sorption positions on Fe oxides (Cowen et al., 1991), so the effect of soil properties should have been apparent also in the case of this metal. The existence of competitive sorption processes between $\mathrm{Pb}$ and $\mathrm{Cd}$ for high-affinity sorption sites on Fe oxides could explain the different effect of the soil factor, as the greater affinity of $\mathrm{Pb}$ by these surface sorption sites pro- 

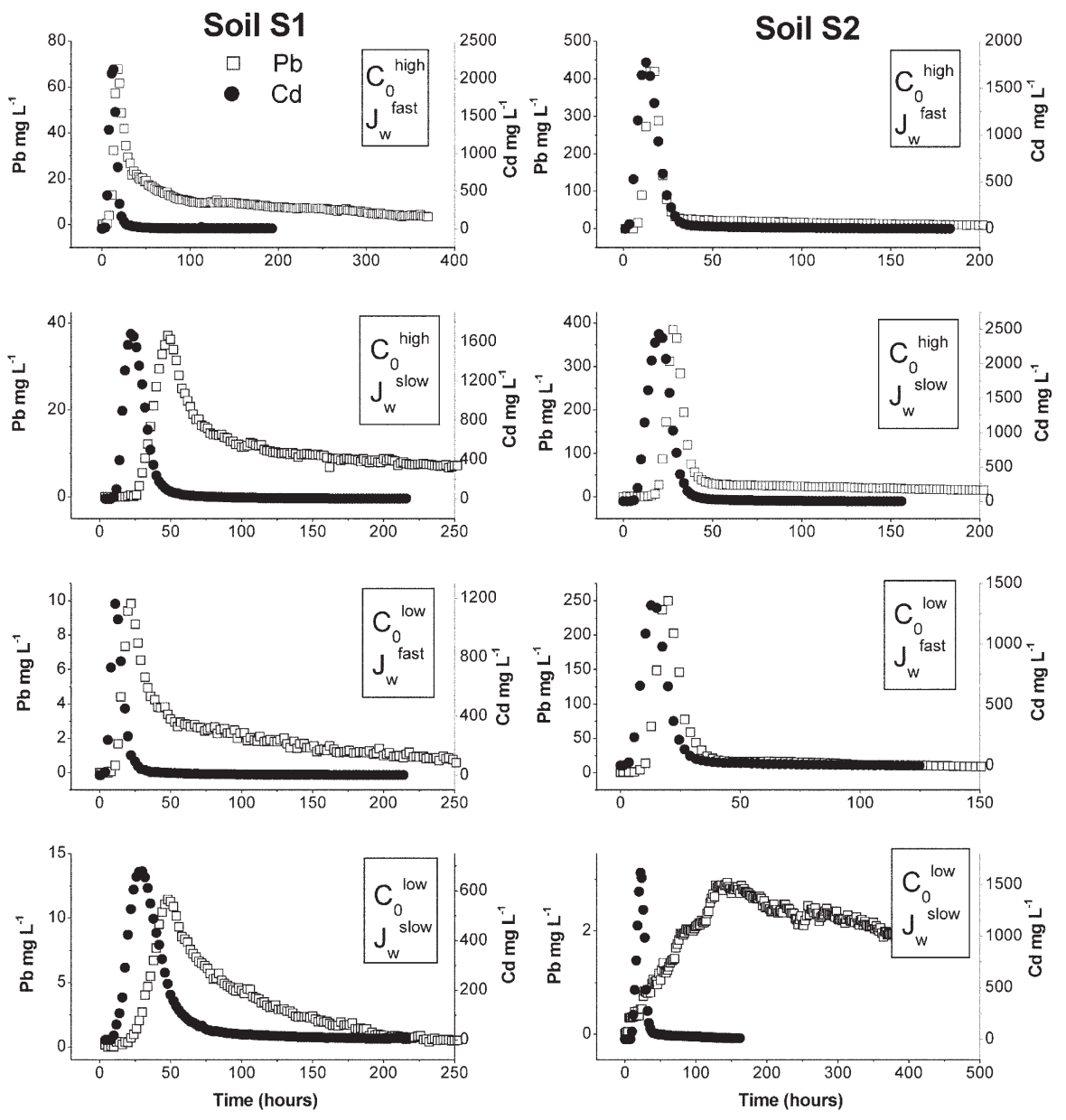

Fig. 1. Breakthrough curve data for $\mathrm{Pb}$ and $\mathrm{Cd}$ in soil columns under different water flux rates $\left(\mathrm{J}_{\mathrm{w}}\right)$ and initial metal concentration $\left(C_{0}\right)$. Values of $J_{\mathrm{w}}$ and $C_{0}$ are shown in Table 3.

motes the displacement of $\mathrm{Cd}$ from these positions, resulting in Cd transport patterns that were less sensitive to the Fe oxide content of the soils.

The effect of water flux on metal retention has already been studied, with contradictory results (Bajracharya et al., 1996; Tran et al., 1998). As theoretically deduced by Nkedi-Kizza et al. (1984) and similar to the experimental results of Bajracharya et al. (1996) with respect to Cd and Miretzky et al. (2006) for $\mathrm{Zn}$, our results show a significant decrease in the estimated $M_{\mathrm{r}}$ values for $\mathrm{Cd}$ resulting from a decrease in $J_{\mathrm{w}}$ in all experimental cases. Other researchers, however, have observed increasing mass recovery rates of $\mathrm{Cd}$ as a result of an increment in water flux (Akratanakul et al., 1983) or an inconclusive relationship between pore water velocity and the mass of metal retained in the soil matrix (Bajracharya et al., 1996). A similar dependency of $M_{\mathrm{r}}$ on $J_{\mathrm{w}}$ was found with respect to $\mathrm{Pb}$ although the differences were not significant in all cases.

This effect of $J_{\mathrm{w}}$ on $M_{\mathrm{r}}$ might be a direct result of a decrease of the mean travel time of the metals, as estimated by the significant increment in the $\mu$ mean values, as well as an increase in dispersion estimated by $\sigma^{2}$. High values of $\mu$ and $\sigma^{2}$ facilitate metal diffusion into micropores, promoting greater contact between the metals and the reactive surface of the soil matrix. In addition, low flow rates increase the participation of kinetic-dependent sorption reactions or others, with greater activation energy producing more stable sorption mechanisms, such as the formation of inner sphere complexes that overall induce the retention of metals within the soil matrix.

The effect of the initial metal concentration on $\mathrm{Pb}$ and $\mathrm{Cd}$ transport depends on the experimental conditions established by the other experimental variables considered. In Soil S1, lower values of Cd mass recovery $\left(M_{\mathrm{r}}\right)$ were found at $C_{0}^{\text {high }}$ and at both $J_{\mathrm{w}}^{\text {fast }}$ and $J_{\mathrm{w}}$ slow. These results concur with those of Alesii et al. (1980) but they are not in agreement with Miretzky et al. (2006), who found a lower fraction of $\mathrm{Zn}$ adsorbed in the soil at a higher initial metal concentration than at a lower one. On the other hand, the effect of the initial metal concentration in Soil S2 seemed to depend on the water flow conditions: at $J_{\mathrm{w}}^{\text {fast }}$, $\mathrm{Cd} M_{\mathrm{r}}$ decreased as $C_{0}$ increased, while at $J_{\mathrm{w}}$ slow, the values of $M_{\mathrm{r}}$ obtained at $C_{0}^{\text {high }}$ and $C_{0}^{\text {low }}$ did not show significant differences. Nevertheless, the absolute mass of metal retained in both $S 1$ and S2 was always greater at higher $C_{0}$ (for instance, $363 \pm 34$ and $541 \pm 84 \mathrm{mg}$ at slow and fast rates of flow, respectively, in Soil S1) than at low $C_{0}(68 \pm 18$ and $146 \pm 48 \mathrm{mg}$ at slow and fast rates of flow, respectively, also in Soil S1). A similar tendency was found for $\mathrm{Pb}$, which suggests some metal precipitation process or the formation of multinuclear complexes at $C_{0}^{\text {high }}$ values (Sposito, 1984).

Figure 2 shows greater $\mathrm{Pb} M_{\mathrm{r}}$ values at $C_{0}^{\text {high }}$ than those observed at $C_{0}$ low, however, for most of the experimental conditions. This different behavior in the mass balance as a result of the initial metal concentration of the pulse could be related to the maximum sorption capacity of the soils, greater in $S 1$ than in S2. While the $M_{\mathrm{r}}$ value at $J_{\mathrm{w}}^{\text {slow }}$ and $C_{0}^{\text {high }}$ was $6 \pm$ 0.9 and $15 \pm 2 \%$ in Soils S1 and S2, respectively, at $C_{0}^{\text {low }}, M_{\mathrm{r}}$ values were similar in both soils $(1.7 \pm 1.8$ and $1.7 \pm 0.5 \%$ in Soils S1 and S2, respectively).

The effect of $C_{0}$ on the transport parameters $\mu$ and $\sigma^{2}$ was different for $\mathrm{Pb}$ and $\mathrm{Cd}$ and depended on the experimental conditions. While no significant differences were found in the $\mu$ values between the two initial $\mathrm{Cd}$ concentrations in either soil, the $\mu$ values for $\mathrm{Pb}$ in Soil S2 were higher at $C_{0}^{\text {low }}$ than at $C_{0}^{\text {high }}$, which means that low mean travel times are associated with a high initial $\mathrm{Pb}$ concentration of the pulses. Also, higher values of the second temporal moment $\left(\sigma^{2}\right)$ were found to be associated with a lower initial $\mathrm{Pb}$ concentration in Soil S2, resulting in greater spreading of the distribution along the $x$ axis. These results were corroborated by Murali and Aylmore (1980), who observed the influence of the initial metal concentration on the transport characteristics and metal retention. Therefore, if the metal mass retained in the soil is high with respect to the sorption capacity of the soil, then high $C_{0}$ values are related to low $\mu$ values. This effect is attributed to the nonlinearity of the sorp- 
tion processes that induce an increase in the metal displacement as the initial metal concentration increases and thus a lower dispersion of the BTC (Naidu et al., 1997).

\section{Initial Conditions and Sorption Patterns}

The effect of the initial conditions (soil, metal, $C_{0}$, and $J_{\mathrm{w}}$ ) on the sorption patterns at two depths as described by the group of fractions obtained from the sequential extraction procedure $\left(F^{\mathrm{I}}, F^{\mathrm{II}}, F^{\mathrm{III}}, F^{\mathrm{IV}}, F^{\mathrm{V}}\right.$, and $\left.F^{\text {Tot }}\right)$ are shown in Table 4 for Soils S1 and S2. The results reveal a metal distribution in the soils that was highly dependent on the experimental conditions established by the different variables considered in this study, so that we were not able to describe a consistent sorption pattern. Some interesting conclusions were possible from the statistical analysis, however, and are shown below.

\section{Influence of Soil Type and Mineralogy}

The different physical, chemical, and mineralogical characteristics of both soils induced significant differences between the total metal concentrations retained in each soil (Table 4). The higher $\mathrm{Pb}$ and $\mathrm{Cd}$ total fraction adsorbed in Soil S1 than in Soil S2 corroborate the higher sorption capacity of the first soil with respect to the second one, as was shown by Serrano et al. (2005).

The metal mass observed in the different chemical extraction fractions in both soils were influenced by the experimental conditions, so that not all the fractions showed significant differences between Soils S1 and S2. For instance, the Cd fraction retained in the exchangeable metal fraction $\left(F^{\mathrm{I}}\right)$ was higher in Soil S2 than in Soil S1 at $J_{\mathrm{w}}^{\text {fast }}$. At lower water flow, however, the Cd fractions retained in $F^{\mathrm{I}}$ of both Soils S1 and S2 did not show significant differences (Table 4).

The $\mathrm{Pb}$ fraction sorbed in $F^{\mathrm{I}}$ was higher in Soil S2 than in Soil S1 at both $J_{\mathrm{w}}$ fast and $J_{\mathrm{w}}$ slow, which suggests an easier metal displacement from the exchange sites in Soil S1. The composition of phyllosilicates present in the soils, the kaolinite and illite in Soils S1 and S2, respectively, are characterized by the absence of isomorphic substitutions that promote the formation of weak electrostatic and reversible bonding between metals and the sites associated with the ditrigonal cavity of siloxane (Sposito, 1984). Our results indicate a higher global reactivity of the exchange sites in Soil S2 than in Soil S1; however, this hypothesis cannot be verified.

The metal fraction bound to $\mathrm{Mn}$ oxides $\left(F^{\mathrm{III}}\right)$ was significantly different for Cd between soils, being higher in S1 than S2 under all experimental conditions. Not all the experimental cases showed significant differences for Pb between Soil S1 and Soil S2; however, in those cases where significant differences were found, the Pb fraction was greater in Soil S1 than in Soil S2. Because Soil S1 is characterized by a higher fraction of Mn oxides than Soil S2, these results would be initially unexpected. As we saw above, however, the displacement velocity and the metal recovery fraction were higher in S2 than in S1, which suggests less interactive metal displacement in S2 than in S1 and so a lower retention in $F^{\mathrm{III}}$ in Soil S2.

Last, no significant differences were found for $\mathrm{Cd}$ in either $F^{\mathrm{IV}}$ or $F^{\mathrm{V}}$, defined as the fractions bound to amorphous and crystalline $\mathrm{Fe}$ oxides, respectively. For $\mathrm{Pb}$, while the fraction retained in $F^{\mathrm{IV}}$ was generally higher in Soil S1 than in Soil S2,
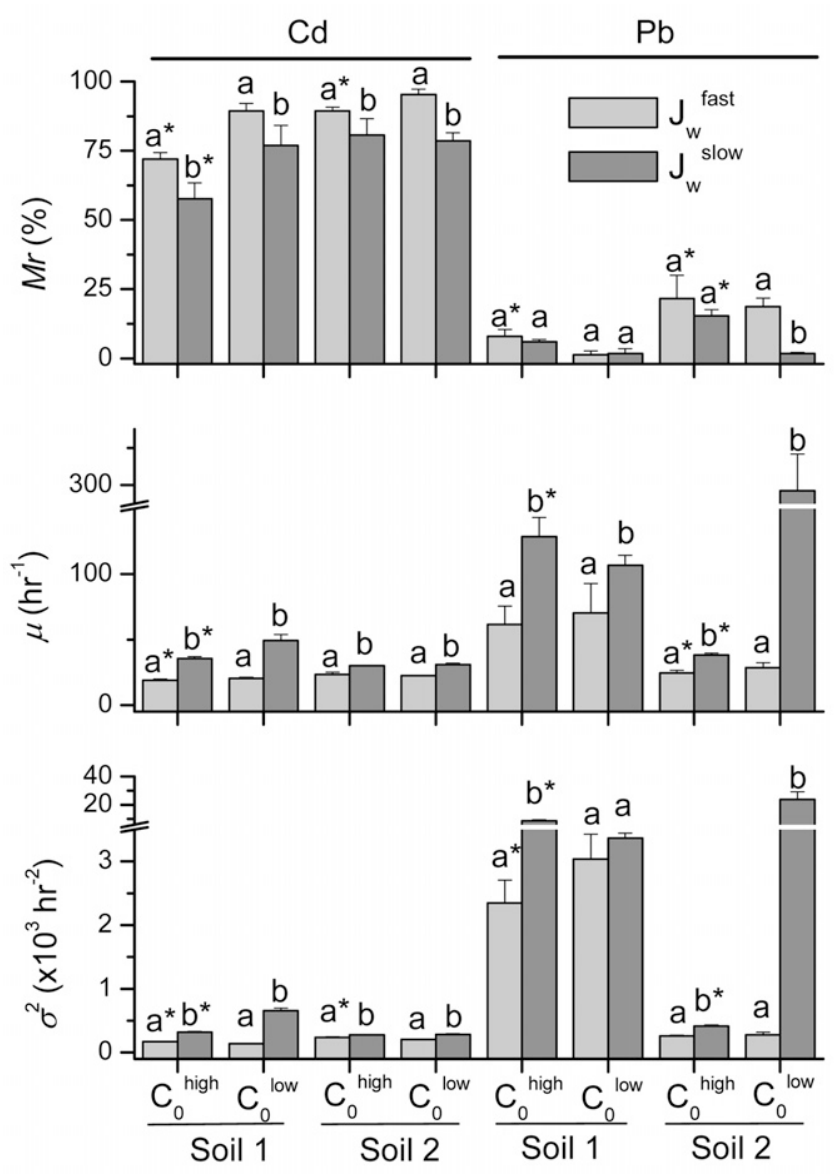

Fig. 2. Mass recovery $\left(M_{r}\right)$, mean travel time $(\mu)$, and vertical solute spreading $\left(\sigma^{2}\right)$ for $\mathrm{Pb}$ and $\mathrm{Cd}$ in two soils under different water flux rates $\left(J_{w}\right)$ and initial metal concentration $\left(C_{0}\right)$. For each metal, soil, and $C_{0}$, different letters indicate statistically significant differences $(P=0.05)$ of the corresponding mean values as a result of different $J_{w}$. For each metal, soil, and $J_{w^{\prime}}$ columns with an asterisk beside the letter indicate statistically significant differences $(P=0.05)$ of the corresponding mean values as a result of different $C_{0}$. Values of $J_{w}$ and $C_{0}$ are shown in Table 3 .

the one adsorbed in $F^{\mathrm{V}}$ was higher in Soil S2 than in Soil S1, showing significant differences between the soils.

\section{Influence of Metal Type}

The different sorption behavior of the two metals in this study was revealed in the analysis of the sequential extraction results. The metal type was one of the sources of variability considered in this study that showed more significant differences in both the total metal retention and the metal distribution along the different fractions defined in the chemical extractions (Fig. 2). The greatest total concentration retained in the soils for all the experimental conditions corresponded to $\mathrm{Pb}$, which once again reflects the higher affinity of the soils for $\mathrm{Pb}$ than $\mathrm{Cd}$. This result was also observed in the higher $\mathrm{Cd}$ displacement along the soil profile respective to $\mathrm{Pb}$, corroborated by the higher $\mathrm{Cd}$ mass recovery relative to $\mathrm{Pb}$. Due largely to its lower tendency to hydrolyze, $\mathrm{Cd}$ is adsorbed on the mineral surface in unstable surface complexes. In addition, studies have revealed that competition among various species for adsorption sites can significantly affect the activity of $\mathrm{Cd}$ in soil solution, and therefore its leaching potential through a soil profile (Serrano et al., 2005). Research has shown that $\mathrm{Ca}^{2+}$ 
Table 4. Metal distribution on the soil solid fractions $\left(F^{\mathrm{I}}-F^{\mathrm{V}}\right)$ and total metal content $\left(F^{\mathrm{Tot}}\right)$ as determined by the sequential extraction procedure.

\begin{tabular}{|c|c|c|c|c|c|c|c|c|c|c|c|c|c|c|}
\hline \multirow{2}{*}{ Depth } & \multirow{2}{*}{$J_{w}+$} & \multirow{2}{*}{$C_{0} \ddagger$} & \multicolumn{6}{|c|}{ Cd } & \multicolumn{6}{|c|}{$\mathbf{P b}$} \\
\hline & & & $F$ & $F^{\prime \prime}$ & $F^{\prime I I I}$ & $F^{\mathrm{IV}}$ & $F^{V}$ & $F^{\text {Tot }}$ & $F$ & $F^{\prime \prime}$ & FIII & $\mathrm{F}^{\mathrm{IV}}$ & $F^{V}$ & $F^{\text {Tot }}$ \\
\hline \multirow[t]{3}{*}{$\mathrm{cm}$} & & & 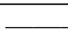 & & $-\%$ & & 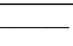 & $\mathrm{mg} \mathrm{kg}^{-1}$ & & & $-\%$ & & & $\mathrm{mg} \mathrm{kg}^{-1}$ \\
\hline & & & & & & & & Soil & & & & & & \\
\hline & & high & 0.7 & 0.3 & 4.9 & 0.2 & 97.6 & 408.3 & 6.4 & 0.7 & 58.7 & 11.2 & 17.6 & 2871.2 \\
\hline \multirow{3}{*}{$0-4$} & fast & low & 1.9 & 0.6 & 10.2 & 0.4 & 88.8 & 252.8 & 8 & 1 & 45.7 & 19.4 & 16.6 & 2288.7 \\
\hline & & high & 3.9 & 0.2 & 6.1 & 0.2 & 90.2 & 520.9 & 3.9 & 0.7 & 44.3 & 20.6 & 20.7 & 3414.2 \\
\hline & slow & low & 1.3 & 0.5 & 6.2 & 0.3 & 83.4 & 374.4 & 6.1 & 0.9 & 44.0 & 18.1 & 22.2 & 2696.2 \\
\hline \multirow[t]{3}{*}{ PSE§ } & & & 0.4 & 0.1 & 0.5 & 0.1 & 3.5 & 28.2 & 0.4 & 0.1 & 2.3 & 0.8 & 0.4 & 135.1 \\
\hline & & high & 0.7 & 0.4 & 3.0 & 0.3 & 80 & 388.6 & 4.4 & 0.9 & 39.9 & 17.1 & 30.8 & 1765.3 \\
\hline & tast & low & 2.5 & 1.0 & 6.4 & 0.9 & 90 & 102.3 & 7.2 & 1 & 38.0 & 14.5 & 26.8 & 1235.1 \\
\hline \multirow{2}{*}{$4-8$} & slop & high & 0.6 & 0.4 & 4.2 & 0.2 & 88.2 & 660.7 & 5.5 & 0.9 & 51.1 & 14.2 & 14.5 & 2477.2 \\
\hline & slow & low & 0.7 & 0.6 & 5.4 & 0.6 & 79.4 & 222.9 & 3.5 & 0.7 & 41.7 & 19.2 & 26.3 & 1769.2 \\
\hline \multirow[t]{4}{*}{ PSE } & & & 0.4 & 0.1 & 0.5 & 0.0 & 5.3 & 30.6 & 0.3 & 0.1 & 1.6 & 1.8 & 0.8 & 79.2 \\
\hline & \multicolumn{14}{|c|}{$\underline{\text { Soil S2 }}$} \\
\hline & \multirow{2}{*}{ fast } & high & 4.9 & 1.7 & 0.9 & 0.3 & 92.9 & 246.6 & 0.7 & 2.4 & 45.0 & 5.9 & 29.9 & 2098.2 \\
\hline & & low & 9.2 & 1.4 & 1.4 & 0.3 & 81.7 & 81.5 & 17.8 & 1.6 & 41.3 & 5.8 & 30 & 1713.4 \\
\hline \multirow[t]{2}{*}{$0-4$} & \multirow{2}{*}{ slow } & high & 2.5 & 2.1 & 1.0 & 0.4 & 93.6 & 278 & 16.0 & 4.1 & 44.3 & 7.5 & 22.5 & 2099.7 \\
\hline & & low & 4.3 & 2.1 & 1.8 & 0.5 & 85.6 & 306.3 & 11.1 & 1.9 & 47.2 & 8.5 & 28.1 & 1920.0 \\
\hline \multirow[t]{3}{*}{ PSE } & & & 1.5 & 0.1 & 0.4 & 0.1 & 3.9 & 27.3 & 1.5 & 0.4 & 1.0 & 0.5 & 0.9 & 37.9 \\
\hline & \multirow{2}{*}{ fast } & high & 1.3 & 4.4 & 0.6 & 0.5 & 90.6 & 117.1 & 15.0 & 3.9 & 6.0 & 18.4 & 59.0 & 620.9 \\
\hline & & low & 5.1 & 10.3 & 1.5 & 0.5 & 98.4 & 19.2 & 10.0 & 3.9 & 29.0 & 11.2 & 45.3 & 582.1 \\
\hline \multirow{2}{*}{$4-8$} & & high & 0.3 & 6.2 & 0.4 & 0.7 & 87.4 & 193 & 10.0 & 2.7 & 21.1 & 4.6 & 50.7 & 967.0 \\
\hline & slow & low & 0.8 & 5.9 & 0.6 & 0.7 & 91.2 & 132.5 & 7.8 & 5.6 & 20.0 & 19.6 & 42.4 & 742.3 \\
\hline PSE & & & 1.1 & 2.9 & 0.3 & 0.1 & 6.1 & 26.5 & 1.2 & 0.6 & 2.3 & 1.4 & 1.1 & 18.9 \\
\hline
\end{tabular}

† Water flux rate as described in Table 3 .

₹ Initial metal concentration as described in Table 3.

$\S$ Pooled standard error for all combinations of $J_{w} \times C_{0}$ and each soil, depth, metal, and fraction.

strongly competes with $\mathrm{Cd}^{2+}$ for exchange sites in soils (Naidu et al., 1994). Consequently, the marked effect of the $\mathrm{CaCl}_{2}$ background electrolyte on Cd displacement was observed for all the chemical extraction fractions. The percentage of $\mathrm{Cd}$ adsorbed in the fractions $F^{\mathrm{I},} F^{\mathrm{III}}$, and $F^{\mathrm{IV}}$ was lower than that of the $\mathrm{Pb}$. Instead, $\mathrm{Cd}$ in $F^{\mathrm{V}}$ was higher than $\mathrm{Pb}$. This indicates that competitive sorption was occurring between $\mathrm{Ca}$ and $\mathrm{Cd}$ except in the fraction corresponding to crystalline $\mathrm{Fe}$ oxides, where $\mathrm{Cd}$ is strongly retained through specific sorption reactions (Table 4).

\section{Influence of Initial Metal Concentration}

The effect of the initial metal concentration on the metal total retention on the soils is shown in Table 4. As can be observed, an increase in the $\mathrm{Pb}$ and $\mathrm{Cd}$ total mass adsorbed in the soils was observed as a result of the increase in the initial metal concentration values. Higher significant differences were found for Cd at Depth $2(4-8 \mathrm{~cm})$ than at Depth $1(0-4$ $\mathrm{cm})$ at both $J_{\mathrm{w}}^{\text {fast }}$ and $J_{\mathrm{w}}^{\text {slow }}$ in Soil S1. While the concentration of $\mathrm{Cd}$ retained in the soils increased from $C_{0}^{\text {high }}$ to $C_{0}^{\text {low }} 1.5$ times and 3.2 times at Depths 1 and 2, respectively, the total $\mathrm{Pb}$ adsorbed increased 1.2 and 1.4 times at Depths 1 and 2, respectively. These results could be attributed to the more homogeneous water flow distribution at Depth 2, and so a higher contact between the metal in the soil solution and the mineral surface than at Depth 1 (Garrido et al., 2001). In the same way, the higher $\mathrm{Cd}$ mobility and the lower affinity for the specific sites with respect to the $\mathrm{Pb}$ resulted in greater differences between depths for $\mathrm{Cd}$ than for $\mathrm{Pb}$.
On the other hand, the $\mathrm{Pb}$ and $\mathrm{Cd}$ distribution along the chemical fractions as a function of the initial metal concentration may depend on the experimental conditions and, in most cases, did not show significant differences; however, the effect of the initial concentration on the metal retained in the $F^{\mathrm{I}}$ fraction is noticeable (Table 4). The estimated ionic strength $(I)$ of the metal pulses is 125.2 and $60.8 \mathrm{mmol} \mathrm{L}^{-1}$ for $C_{0}$ high and $C_{0}^{\text {low }}$, respectively, in the case of Soil S1. For Soil S2, these values are 100.9 and $72.3 \mathrm{mmol} \mathrm{L}^{-1}$ for $C_{0}^{\text {high }}$ and $C_{0}$ low, respectively. The effect of $I$ on metal sorption is difficult to assess. On the one hand, increasing $I$ may yield an increment of surface charge in variable-charge soils (Naidu et al., 1997), which provides these soils with greater sorption capacity. On the other hand, increasing $I$ may also decrease metal sorption through changes in metal activities (depending on the background electrolyte), competition for the sorption sites (depending on the index cation), and changes in the electrostatic potential of the plan of sorption (depending on $\mathrm{pH}$ and soil mineral properties) (Naidu et al., 1994). While insensitivity to $I$ has been understood as an indication of inner sphere surface complexation, however, a decrease of sorption with increasing $I$ has been associated with outer sphere surface complexation sorption processes (Lützenkirchen, 1997). Attending to the results of the sequential chemical extraction (Table 4), the concentration of $\mathrm{Cd}$ in $F^{\mathrm{I}}$ (ascribable to outer sphere sorption mechanisms) is lower at $C_{0}$ high (high $I$ ) than at $C_{0}^{\text {low }}$ (low I) at both depths for both soils. This tendency was not found for $\mathrm{Pb}$. The higher tendency of $\mathrm{Cd}$ to be retained in nonspecific sites compared with $\mathrm{Pb}$ could explain the higher 
Table 5. Regression coefficients associated with the sorption parameters as independent variables selected to describe the first and second temporal moments (mean travel time $\mu$ and vertical solute spreading $\sigma^{2}$, respectively) and mass recovery $\left(M_{\mathrm{r}}\right)$ for soil solid fractions $F^{\mathrm{l}}$ through $F^{V}$ from the sequential extraction procedure.

\begin{tabular}{|c|c|c|c|c|c|c|c|c|}
\hline \multirow{2}{*}{ Parameter } & \multirow{2}{*}{ Soil } & \multirow{2}{*}{ Metal } & \multicolumn{5}{|c|}{ Regression coefficients \pm SE } & \multirow{2}{*}{$R$} \\
\hline & & & $F^{I}$ & $F^{\text {II }}$ & $F^{\text {III }}$ & $F^{\mathrm{IV}}$ & $F^{V}$ & \\
\hline \multirow{4}{*}{$\mu$} & \multirow{2}{*}{ S1 } & $\mathrm{Cd}$ & & $-6.7 \pm 8.9$ & & & $-0.6 \pm 0.3$ & 0.41 \\
\hline & & $\mathrm{Pb}$ & $-18.8 \pm 4.6$ & $90.1 \pm 44.5$ & $-1.7 \pm 0.9$ & & $-5.1 \pm 1.3$ & 0.74 \\
\hline & \multirow{2}{*}{ S2 } & $\mathrm{Cd}$ & $-0.9 \pm 0.3$ & & $2.9 \pm 1.4$ & & & 0.56 \\
\hline & & $\mathrm{Pb}$ & $-15.4 \pm 4.6$ & & $5.0 \pm 1.5$ & $13.1 \pm 3.8$ & & 0.74 \\
\hline \multirow{4}{*}{$\sigma^{2}$} & \multirow{2}{*}{ S1 } & $\mathrm{Cd}$ & $-32.4 \pm 38.7$ & $-89.4 \pm 168.7$ & $12.6 \pm 24.6$ & & $-9.9 \pm 5.2$ & 0.82 \\
\hline & & $\mathrm{Pb}$ & $-1514.0 \pm 331.1$ & $6663 \pm 3229$ & $-151.1 \pm 70.1$ & & $-518 \pm 97$ & 0.73 \\
\hline & \multirow{2}{*}{ S2 } & $\mathrm{Cd}$ & $-8.7 \pm 2.3$ & $-3.3 \pm 1.3$ & $17.5 \pm 11.0$ & $36.5 \pm 25.2$ & & 0.74 \\
\hline & & $\mathrm{Pb}$ & $-1426.8 \pm 433.9$ & $-1085 \pm 1523$ & $469 \pm 143$ & $1425 \pm 453$ & $0.1 \pm 0.3$ & 0.76 \\
\hline \multirow{4}{*}{$M_{\mathrm{r}}$} & \multirow{2}{*}{ S1 } & $\mathrm{Cd}$ & $-4.4 \pm 1.4$ & & $3.1 \pm 0.8$ & $30.9 \pm 6.8$ & & 0.83 \\
\hline & & $\mathrm{Pb}$ & $-1.1 \pm 0.3$ & & $0.1 \pm 0.1$ & $-0.4 \pm 0.2$ & & 0.67 \\
\hline & \multirow{2}{*}{ S2 } & $\mathrm{Cd}$ & $1.7 \pm 0.4$ & $0.9 \pm 0.3$ & & $-4.0 \pm 5.5$ & $0.1 \pm 0.1$ & 0.74 \\
\hline & & $\mathrm{Pb}$ & $0.8 \pm 0.4$ & & $-0.2 \pm 0.3$ & $-0.9 \pm 0.4$ & $0.1 \pm 0.3$ & 0.61 \\
\hline
\end{tabular}

influence of $C_{0}$ (i.e., $I$ ) on $C d$ retention on the ionic exchange sites compared with that of $\mathrm{Pb}$.

\section{Influence of Flow Rate}

The total metal mass retained in the soils was greatly influenced by the water flux rate used in the displacement experiments. In general, higher values of the metal mass adsorbed were found at lower water flux (Table 4). At slow water flow velocity, the equilibrium conditions could be reached more easily than at higher flow rates, and thus the metal can be retained on specific sites through very stable complexes that are not easily displaced (Sparks, 1984). This result, therefore, suggests chemical nonequilibrium transport conditions at the higher flow rate.

In addition, faster flow velocities may favor transport in fast flow pathways (like macropores) and slower transport velocities may allow a greater influence of the soil matrix (smaller pores) (Dyson and White, 1989). So at the slower flow rate, the solute is actually physically interacting with a larger proportion of the total soil volume or effective porosity. This effect could also result in physical nonequilibrium transport conditions at the higher flow rate.

The effect of water flux on metal adsorption in the different sequential soil fractions was not conclusive. The more important effect was found in $F^{\mathrm{I}}$. In general, both $\mathrm{Pb}$ and $\mathrm{Cd}$ retained in $F^{\mathrm{I}}$ were higher at $J_{\mathrm{w}}$ fast than at $J_{\mathrm{w}}$ slow. These results are consistent with Pang et al. (2002), who showed an increase in the $\mathrm{Pb}$ and $\mathrm{Cd}$ sorption phenomena and the metal mass recovered with increasing water flow in soil columns (Table 4).

\section{Depth Differences in Sorption}

Last, the depth variable showed the greatest influence on the total metal mass retained in the soils. As can be seen in Table 4, for most of the experimental conditions a higher $\mathrm{Pb}$ and Cd metal fraction was found at Depth $1(0-4 \mathrm{~cm})$ than at Depth $2(4-8 \mathrm{~cm})$. It has been shown that, in structured soils, uniformly applied solutes tend to be focused into preferential flow pathways (Fluehler et al., 1996). If this focusing were to occur, it would result in a greater contact between the solute and soil at Depth 1 than at Depth 2, where less contact with the soil could affect mass retention deeper in the soil.

\section{Statistical Relationships between Initial Conditions and Transport Linear Regression: Sorption and Transport Parameters}

The result of the regression analysis for studying the linear relationships between each transport parameter $\left(\mu, \sigma^{2}\right.$, and $\left.M_{\mathrm{r}}\right)$ and the whole sorption parameters $\left(F^{\mathrm{I}}, F^{\mathrm{II}}, F^{\mathrm{III}}, F^{\mathrm{I} V}\right.$, and $F^{V}$ ) is shown in Table 5. This procedure does not consider the effect of the variability factors $J_{\mathrm{w}}, C_{0}$, and depth, thus the model adjustment level for each transport parameter depends on the experimental conditions established by the combination metal $\times$ soil. As can be observed in the tables, the model does not provide a complete representation of transport for all the experimental cases. The lack of adjustment level could be due to variables not taken into account in this regression analysis. While a complete model was not possible, some conclusions were possible and are discussed here.

First Temporal Moment. The results of the regression model for the first temporal moment $(\mu)$ showed a higher adjusting level for $\mathrm{Pb}$ than for $\mathrm{Cd}$. With the exception of one result corresponding to $\mathrm{Cd}$ in Soil S1, the model coefficients associated with $F^{\mathrm{I}}$ were negative and significant for all experimental conditions (Table 5). These results suggest that, independent of the initial metal concentration or the flow rate, the mean displacement time of the metals was greatly influenced by the exchange reactions between the metals and the soil matrix.

It is also interesting that in Soil $\mathrm{S} 2$, both $\mathrm{Pb}$ and $\mathrm{Cd}$ were observed to have high positive model coefficients for the $F^{\mathrm{III}}$ fractions associated with high values of $\mu$ (i.e., slower metal travel time). In addition, the $\mathrm{Pb}$ retention on the amorphous $\mathrm{Fe}$ oxides $\left(F^{\mathrm{IV}}\right)$ contributed to predicted first temporal moments, similar to that observed with $F^{\mathrm{III}}$ (Table 5). These results suggest that the semi-irreversible character of the $\mathrm{Pb}$ sorption process on the Mn and Fe oxides is related to a slow metal transport phenomenon.

In Soil $\mathrm{S} 1$ for $\mathrm{Pb}$, besides $F^{\mathrm{I}}$, the $F^{\mathrm{II}}$ and $F^{\mathrm{V}}$ appear as predictive variables to explain $\mu$. The first temporal moment is related positively to the $F^{\mathrm{II}}$ coefficient and negatively to the $F^{\mathrm{V}}$ coefficient. The high affinity of $\mathrm{Pb}$ for the specific sites associated with organic matter (Sposito, 1984; Basta et al., 1993) resulted in a low metal displacement time. We are unable to 
Table 6. Canonical correlation analysis for $\mathrm{Cd}$.

\begin{tabular}{cccccc} 
Function & $\begin{array}{c}\text { Canonical } \\
\text { correlation }\end{array}$ & Eigenvalue & Difference & Proportion & Cumulative \\
\hline 1 & 0.684 & 0.878 & 0.741 & 0.859 & 0.859 \\
2 & 0.347 & 0.136 & 0.130 & 0.133 & 0.993 \\
3 & 0.082 & 0.006 & & 0.006 & 1.000 \\
\hline
\end{tabular}

offer any good explanation for the negative coefficient associated with $F^{\mathrm{V}}$ (Table 5); however, the fact that $\mathrm{Pb}$ has a high affinity for $\mathrm{Fe}$ oxides could suggest that an important concentration of this metal does not participate in the transport processes and consequently the BTC area decreases, producing a decrease in $\mu$ as a result of a collateral effect.

Second Temporal Moment. The model results for the second temporal moment were similar for both metals in Soil S2 (Table 5). In this soil, the coefficients associated to $F^{\mathrm{I}}$ and $F^{\mathrm{II}}$ were negative, while those associated with $F^{\mathrm{III}}$ and $F^{\mathrm{IV}}$ were positive. The metal retention on the exchange sites associated with phyllosilicates and organic matter may be described by assuming instantaneous equilibrium and nonchemical hysteresis (Seuntjens et al., 2001). Consequently, a greater tendency for sorption on these sites is associated with a more convective transport and more symmetrical (low $\sigma^{2}$ values) shapes of the BTC. On the other hand, metal retention on the specific sites occurs through semi-irreversible sorption processes under physical or chemical nonequilibrium conditions. The metal retention on these specific sites promotes more dispersive BTCs and thus higher $\sigma^{2}$ values. Assuming that it is not easy to establish differences between chemical and physical nonequilibrium conditions, the fact that most of the variance associated with $\sigma^{2}$ can be explained by these sorption parameters could indicate that the metal behavior during the transport processes was more affected by the sorption processes (chemical nonequilibrium) than by the diffusion processes that were taking place in the micropores of the soil structure (physical nonequilibrium).

Since low $R$ values were obtained in the regression analysis for Cd in Soil S1, no conclusions could be extracted from the results. The analysis results for $\mathrm{Pb}$, however, showed that all the sorption variables (with the exception of $F^{\mathrm{IV}}$ ) took part in the description of the second temporal moment $\left(\sigma^{2}\right)$. Once again, the coefficient associated with $F^{\mathrm{I}}$ was negatively related to $\sigma^{2}$, while the one associated with $F^{\mathrm{II}}$ was positive. This result corroborates the study of Basta et al. (1993), which showed a tendency for $\mathrm{Pb}$ to be retained on organic matter through inner sphere complexes, which induces asymmetric leaching curves characterized by high $\sigma^{2}$ values.

Mass Balance. The model results for the mass balance $\left(M_{\mathrm{r}}\right)$ for all the experimental conditions established by the combination metal $\times$ soil showed higher $R$ values than the ones obtained for the two previous temporal moments. In Soil S1, the fractions $F^{\mathrm{I}}$, $F^{\mathrm{III}}$, and $F^{\mathrm{IV}}$ appear as predictive variables, with significant coefficients for both $\mathrm{Pb}$ and $\mathrm{Cd}$ metals (Table 5). The inconclusive results obtained can be attributed to the effect of the variability factors that have not been taken into account in the leaching experiments. For instance, while it would be expected that higher mass balances would be associated with a larger fraction of metal retained on the exchange sites, the negative coefficient associated with $F^{\mathrm{I}}$ for both metals showed the contrary. These results could suggest a metal displacement process by the $\mathrm{Ca}$ cation present in the solution that increased the values of the mass of metal recovered in the leachate with respect to the initial mass added to the soil column.

\section{Canonical Correlation Analysis}

The statistical relationship between the whole sorption parameter group and the transport parameters was studied in a multivariant way through a canonical correlation analysis. This analysis provides the best combination of sorption parameters that explains the whole transport phenomenon as defined by the three transport parameters that jointly represent the metal BTCs.

This procedure defines as many double canonical functions (canonical variables) as the least number of variables within each variable group-in this case, three. In the case of $\mathrm{Cd}$, the first canonical function, which describes $86 \%$ of the variance (Table 6), can be interpreted by the correlations between the variables from both groups of parameters and their first canonical variable (Table 7). Each of these coefficients provides information on the multivariant functional relationship that operates between both variable groups. This way, the sorption variables $F^{\mathrm{I}}, F^{\mathrm{II}}$, and $F^{\mathrm{IV}}$ and the transport variable $M_{\mathrm{r}}$ showed the highest weight in the canonical correlation and both groups of variables are positively related. On the other hand, the sorption variable group is also negatively related to the first and second temporal moments. Overall, the relationship between both sorption and transport variable groups could be represented as

$$
\left\{F^{\mathrm{I}}, F^{\mathrm{II}}, F^{\mathrm{IV}}\right\}^{+} \leftrightarrow\left\{M_{\mathrm{r}}\right\}^{+} \cup\left\{\mu, \sigma^{2}\right\}^{-}
$$

These multivariant relationships indicate the inverse relation between both $\mu$ and $\sigma^{2}$ temporal moments and the mass balance $\left(M_{\mathrm{r}}\right)$. Therefore, as the mass of metal in the leachate increases, the mean displacement time of the solute increases and the spreading of the distribution of the BTC decreases. These results indicate that $\mathrm{Cd}$ transport is convective and is regulated by the sorption parameters $F^{\mathrm{I}}, F^{\mathrm{II}}$, and $F^{\mathrm{IV}}$.

The second component explains $14 \%$ of the variance (Table 6) and the sorption $F^{\mathrm{V}}$ variable is related to the first and second temporal moments through the expression (Table 7)

$$
\left\{F^{\mathrm{v}}\right\}^{-} \leftrightarrow\left\{\mu, \sigma^{2}\right\}^{+}
$$

This expression indicates that low values associated with $F^{\mathrm{V}}$ are related to high values of $\mu$ and $\sigma^{2}$, which suggest the irreversible character of the sorption processes on $F^{V}$. The metals retained though irreversible sorption are not easily displaced from the sorption sites, making the BTCs more compressed and thus decreasing the values of the temporal moments.

The results of the canonical analysis correlation for $\mathrm{Pb}$ showed two canonical functions that represent $98 \%$ of the variance (Table 8). The first canonical function, which describes $86.6 \%$ of the variance, can be interpreted by the correlation between the variables from both groups of parameters and their own first canonical variable (Table 9). Attending to these correlations, the following interparametric expression is suggested:

$$
\left\{F^{\mathrm{I}}, F^{\mathrm{II}}, F^{\mathrm{V}}\right\}^{+} \cup\left\{F^{\mathrm{III}}, F^{\mathrm{IV}}\right\}^{-} \leftrightarrow\left\{M_{\mathrm{r}}\right\}^{+} \cup\left\{\mu, \sigma^{2}\right\}^{-}
$$


Table 7. Correlations between the soil solid fraction from sequential fractionation $\left(F^{\mathrm{I}}, F^{\mathrm{II}}, F^{\mathrm{III}}, F^{\mathrm{IV}}\right.$, and $\left.F^{\mathrm{V}}\right)$ and moments variables of mean travel time $(\mu)$, vertical solute spreading $\left(\sigma^{2}\right)$ and mass recovery $\left(M_{\mathrm{r}}\right)$ and their canonical variables for $\mathrm{Cd}$.

\begin{tabular}{lcc}
$\begin{array}{c}\text { Fraction or moment } \\
\text { variable }\end{array}$ & $\begin{array}{c}\text { Correlation } \\
\text { First canonical } \\
\text { variable }\end{array}$ & $\begin{array}{c}\text { Second canonical } \\
\text { variable }\end{array}$ \\
\hline$F^{\mathrm{I}}$ & 0.636 & -0.138 \\
$F^{\mathrm{II}}$ & 0.563 & 0.035 \\
$F^{\mathrm{III}}$ & -0.279 & 0.282 \\
$F^{\mathrm{IV}}$ & 0.583 & 0.366 \\
$F^{\mathrm{V}}$ & 0.100 & -0.904 \\
$M_{\mathrm{r}}$ & 0.917 & -0.025 \\
$\mu$ & -0.393 & 0.919 \\
$\boldsymbol{\sigma}^{2}$ & -0.395 & 0.871 \\
\hline
\end{tabular}

The $\mathrm{Pb}$ transport is mainly regulated by the sorption fractions $F^{\mathrm{I}}, F^{\mathrm{II}}$, and $F^{\mathrm{V}}$, which are related to high values of the metal mass leached $\left(M_{\mathrm{r}}\right)$ and transport conditions close to the physical or chemical equilibrium (low $\mu$ and $\sigma^{2}$ values). Opposite to these fractions, $F^{\mathrm{III}}$ and $F^{\mathrm{I} V}$, associated with semi-irreversible sorption mechanisms, are related to a lower mass balance (low $M_{\mathrm{r}}$ values), a lower mean displacement time (high $\mu$ values), and a higher dispersion level (high $\sigma^{2}$ values).

Last, it should be mentioned that the expression corresponding to the second canonical function (Table 9) can be represented by

$$
\left\{F^{\mathrm{II}}\right\}^{+} \leftrightarrow\left\{\mu, \sigma^{2}\right\}^{+}
$$

This interparametric relationship indicates the semi-irreversible sorption mechanism of $\mathrm{Pb}$ on the organic matter fraction related to a slow mean displacement time and high dispersion levels.

\section{CONCLUSIONS}

This study investigated the sorption behavior of $\mathrm{Pb}$ and $\mathrm{Cd}$ during nonequilibrium transport in undisturbed columns of two acidic soils. We examined the effect of initial conditions including soil (S1 and $\mathrm{S} 2)$, metal $(\mathrm{Pb}$ and $\mathrm{Cd})$, metal initial concentration $\left(C_{0}\right)$, and water flux rate $\left(J_{\mathrm{w}}\right)$ on $\mathrm{Pb}$ and $\mathrm{Cd}$ transport and sorption processes at two depths $(0-4$ and 4-8 $\mathrm{cm})$. In addition, statistical relationships between both sorption and transport phenomena were examined in detail.

The transport parameters obtained from the BTC's temporal moments analysis indicated that $\mathrm{Cd}$ transport is characterized by larger mass recovery values $\left(M_{\mathrm{r}}\right)$ and lower estimated values of the transport travel time $(\mu)$ and solute spreading with time $\left(\sigma^{2}\right)$ than those observed for $\mathrm{Pb}$. This indicates the higher affinity for $\mathrm{Pb}$ to be retained in the soil matrix with respect to $\mathrm{Cd}$ and the higher mobility of $\mathrm{Cd}$ relative to $\mathrm{Pb}$. In addition, lower metal mass recovery values $\left(M_{\mathrm{r}}\right)$ were obtained when the metal transport occurred at low water flow rates.

On the other hand, the initial conditions of soil type and metal species produced significant differences in the mass fractions obtained from the chemical sequential extraction. The initial concentration $\left(C_{0}\right)$ was directly related to the total metal mass retained; however, the effect of $C_{0}$ on the sorption fractions was dependent on the metal species, so a sorption pattern cannot be established.
Table 8. Canonical correlation analysis for $\mathrm{Pb}$.

\begin{tabular}{cccccc} 
Function & $\begin{array}{c}\text { Canonical } \\
\text { correlation }\end{array}$ & Eigenvalue & Difference & Proportion & Cumulative \\
\hline 1 & 0.762 & 1.387 & 1.198 & 0.866 & 0.866 \\
2 & 0.398 & 0.188 & 0.162 & 0.117 & 0.983 \\
3 & 0.159 & 0.026 & & 0.016 & 1.000 \\
\hline
\end{tabular}

In addition, the results of the statistical study showed a relationship between sorption and transport parameters, indicating that $\mathrm{Cd}$ transport was regulated by $F^{\mathrm{I}}, F^{\mathrm{II}}$, and $F^{\mathrm{IV}}$, which are inversely related to $M_{\mathrm{r}}$ and directly related to $\mu$ and $\sigma^{2}$. In the case of $\mathrm{Pb}$, the fractions that regulate transport are $F^{\mathrm{I}}, F^{\mathrm{II}}$, and $F^{\mathrm{V}}$, which were also directly related to $\mu$ and $\sigma^{2}$ and inversely to $M_{\mathrm{r}}$. The different experimental approaches in this study, including BTC analysis and sequential extraction performed in combination with statistical analyses, revealed complicated patterns in $\mathrm{Pb}$ and $\mathrm{Cd}$ reactive transport, indicating physical and chemical nonequilibrium. These results demonstrate that characterization and modeling of $\mathrm{Pb}$ and $\mathrm{Cd}$ transport in heterogeneous soils require techniques that do not assume physical and chemical equilibrium.

\section{REFERENCES}

Adriano, D.C.2001. Traceelements in terrestial environments. Biogeochemistry, bioavailability, and risks of metals. 2nd ed. Springer-Verlag, New York. Aguilar, J., C. Dorronsoro, E. Fenández, J. Fernández, I. García, F. Martín, and M. Simón. 2004. Soil pollution by pyrite mine spill in Spain: Evolution in time. Environ. Pollut. 132:395-401.

Akratanakul, S., L. Boersma, and G.O. Klock. 1983. Sorption process in soils as influenced by pore water velocity: II Experimental results. Soil Sci. 135:331-341.

Alesii, B.A., W.H. Fuller, and M.V. Boyle. 1980. Effect of leachate flow on metal migration through soil. J. Environ. Qual. 9:119-126.

Allison, J.D., D.S. Brown, and K.J. Novo-Gradac. 1991. MINTEQA2/ PRODEFA2, a geochemical assessment model for environmental systems: Version 3.0 user's manual. USEPA Environ. Res. Lab., Athens, GA.

Bajracharya, K., Y.T. Tran, and D.A. Barry. 1996. Cadmium adsorption at different pore water velocities. Geoderma 73:197-216.

Barnhisel, R., and P.M. Bertsch. 1982. Aluminum. p. 275-300. In A.L. Page et al. (ed.) Methods of soil analysis. Part 2. Chemical and microbiological properties. Agron. Monogr. 9. ASA and SSSA, Madison, WI.

Basta, N.T., D.J. Pantone, and M.A. Tabatabai. 1993. Path analysis of heavy metal adsorption by soil. Agron. J. 85:1054-1057.

Bradbury, M.H., and B. Baeyens. 2005. Experimental measurements and modeling of sorption competition on montmorillonite. Geochim. Cosmochim. Acta 69:4187-4197.

Brusseau, M.L., R.E. Jessup, and P.S.C. Rao. 1989. Modelling the transport of solutes

Table 9. Correlations between the soil solid fraction from sequential fractionation $\left(F^{\mathrm{I}}, \boldsymbol{F}^{\mathrm{II}}, \boldsymbol{F}^{\mathrm{III}}, \boldsymbol{F}^{\mathrm{V}}\right.$ and $\left.\boldsymbol{F}^{\mathrm{V}}\right)$ and moments variables of mean travel time $(\mu)$, vertical solute spreading $\left(\sigma^{2}\right)$ and mass recovery $\left(M_{r}\right)$ and their canonical variables for $\mathrm{Pb}$.

\begin{tabular}{lcc} 
Fraction or moment & \multicolumn{2}{c}{ Correlation } \\
\cline { 2 - 3 } variable & $\begin{array}{c}\text { First canonical } \\
\text { variable }\end{array}$ & $\begin{array}{c}\text { Second canonical } \\
\text { variable }\end{array}$ \\
\hline$F^{\mathrm{I}}$ & 0.792 & -0.102 \\
$F^{\mathrm{II}}$ & 0.673 & 0.632 \\
$F^{\mathrm{III}}$ & -0.577 & 0.010 \\
$F^{\mathrm{IV}}$ & -0.739 & 0.096 \\
$F^{\mathrm{V}}$ & 0.734 & 0.063 \\
$M_{\mathrm{r}}$ & 0.982 & -0.155 \\
$\mu$ & -0.454 & 0.881 \\
$\sigma^{2}$ & -0.312 & 0.947 \\
\hline
\end{tabular}


influenced by multiprocess nonequilibrium. Water Resour. Res. 25:1971-1988.

Camobreco, V.J., B.K. Richards, T.S. Steenhuis, J.H. Peverly, and M.B. McBride. 1996. Movement of heavy metals through undisturbed and homogenized soil columns. Soil Sci. 161:740-750.

Campbell, C.G., F. Garrido, V. Illera, and M.T. Garcia-Gonzalez. 2006. Transport of $\mathrm{Cd}, \mathrm{Cu}$ and $\mathrm{Pb}$ in an acid soil amended with phosphogypsum, sugar foam and phosphoric rock. Appl. Geochem. 21:1030-1043.

Chen, C.-C., and K.F. Hayes. 1999. X-ray absorption spectroscopy investigation of aqueous $\mathrm{Co}(\mathrm{II})$ and $\mathrm{Sr}(\mathrm{II})$ sorption at clay-water interfaces. Geochim. Cosmochim. Acta 63:3205-3215.

Chlopecka, A., and D.C. Adriano. 1996. Mimicked in-situ stabilization of metals in a cropped soil: Bioavailability and chemical form of zinc. Environ. Sci. Technol. 30:3294-3303.

Cowen, C.E., J.M. Zachara, and C.T. Resch. 1991. Cadmium adsorption on iron oxides in the presence of alkaline-earth elements. Environ. Sci. Technol. 25:437-446.

Dyson, J.S., and R.E. White. 1989. A simple predictive approach to solute transport in layered soils. J. Soil Sci. 40:525-542.

Fluehler, H., W. Durner, and M. Flury. 1996. Lateral solute mixing processes: A key for understanding field-scale transport of water and solutes. Geoderma 70:165-183.

Förstner, U. 1995. Land contamination by metals: Global scope and magnitude of problem. p. 1-33. In H.E. Allen et al. (ed.) Metal speciation and contamination of soil. Lewis Publ., Boca Raton, FL.

Garrido, F., M. Ghodrati, C.G. Campbell, and M. Chendorain. 2001. Detailed characterization of solute transport in a heterogeneous field soil. J. Environ. Qual. 30:573-583.

Hooda, P.S., and B.J. Alloway. 1998. Cadmium and lead sorption behaivior of selected English and Indian soils. Geoderma 84:121-134.

Jury, W.A., and K. Roth. 1990. Transfer functions and solute movement through soil. Birkhauser Verlag, Basel, Switzerland.

Kim, B., and M.B. McBride. 2006. A test of sequential extractions for determining metal speciation in sewage sludge-amended soils. Environ. Pollut. 144:475-482.

Kookana, R.S., and R. Naidu. 1998. Effect of soil solution composition on cadmium transport through variable charge soils. Geoderma 84:235-248.

Lützenkirchen, J. 1997. Ionic strength effects on cation sorption to oxides: Macroscopic observations and their significance in microscopic interpretation. J. Colloid Interface Sci. 195:149-155.

Mallants, D., M. Vanclooster, M. Meddahi, and J. Feyen. 1994. Estimating solute transport in undisturbed soil columns using time-domain reflectometry. J. Contam. Hydrol. 17:91-109.

McBride, M.B. 1994. Environmental chemistry of soils. Oxford Univ. Press, New York.

Miretzky, P., A. Saralegui, and A.F. Cirelli. 2006. Simultaneous heavy metal removal mechanism by dead macrophytes. Chemosphere 62:247-254.

Murali, V., and L.A.G. Aylmore. 1980. No-flow equilibration and adsorption dynamics during ionic transport in soils. Nature 283:467-469.

Naidu, R., N.S. Bolan, R.S. Kookama, and K.G. Tiller. 1994. Ionic-strength and $\mathrm{pH}$ effects on the sorption of cadmium and the surface charge of soils. Eur. J. Soil Sci. 45:419-429.

Naidu, R., R.S. Kookama, M.E. Sumner, R.D. Harter, and K.G. Tiller. 1997. Cadmium sorption and transport in variable charge soils: A review. J.
Environ. Qual. 26:602-617.

Nkedi-Kizza, P., J.W. Biggar, H.M. Selim, M.Th. van Genuchten, P.J. Wierenga, J.M. Davidson, and D.R. Nielsen. 1984. On the equivalence of two conceptual models for describing ion exchange during transport through an aggregated Oxisol. Water Resour. Res. 20:1123-1130.

Pang, L., M. Close, D. Schneider, and G. Stanton. 2002. Effect of pore-water velocity on chemical nonequilibrium transport of $\mathrm{Cd}, \mathrm{Zn}$, and $\mathrm{Pb}$ in alluvial gravel columns. J. Contam. Hydrol. 57:241-258.

Pang, L., M. Goltz, and M. Close. 2003. Application of the method of temporal moments to interpret solute transport with sorption and degradation. J. Contam. Hydrol. 60:123-134.

Papelis, C., and K.F. Hayes. 1996. Distinguishing between interlayer and external sorption sites of clay minerals using $\mathrm{x}$-ray absorption spectroscopy. Colloid Surf. A 107:89-96.

Serrano, S., F. Garrido, C.G. Campbell, and M.T. García-González. 2005. Competitive sorption of cadmium and lead in acid soils of central Spain. Geoderma 124:91-104.

Seuntjens, P., D. Mallants, C. Cornelis, and P. Geuzens. 2001. Nonequilibrium cadmium leaching in layered sandy soils. Soil Sci. 166:507-519.

Shuman, L.M. 1985. Fractionation method for soil microelements. Soil Sci. 140:11-22.

Shuman, L.M. 1990. Comparison of exchangeable Al, extractable Al, and $\mathrm{Al}$ in soil fractions. Can. J. Soil Sci. 70:263-275.

Sparks, D.L. 1984. Ion activities: An historical and theoretical overview. Soil Sci. Soc. Am. J. 48:514-518.

Sposito, G. 1984. The surface chemistry of soils. Oxford Univ. Press, New York.

Soil Survey Staff. 1999. Soil Taxonomy: A basic system of soil classification for making and interpreting soil surveys. 2nd ed. U.S. Gov. Print. Office, Washington, DC.

Strawn, D.G., and D.L. Sparks. 1999. The use of XAFS to distinguish between inner- and outer-sphere lead adsorption complexes on montmorillonite. J. Colloid Interface Sci. 216:257-269.

Tessier,A., P.G.C. Campbell, and M. Bisson. 1979. Sequential extraction procedure for the speciation of particulate trace metals. Anal. Chem. 51:844-851.

Thomas, G.W. 1982. Exchangeable cations. p. 159-164. In A.L. Page et al. (ed.) Methods of soil analysis. Part 2. Chemical and microbiological properties. Agron. Monogr. 9. ASA and SSSA, Madison, WI.

Tran, Y.T., K. Bajracharya, and D.A. Barry. 1998. Anomalous cadmium adsorption in flow interruption experiments. Geoderma 84:169-184.

Valocchi, A.J. 1990. Use of temporal moment analysis to study reactive solute transport in aggregated porous media. Geoderma 46:233-247.

Vercoutere, K., U. Fortunati, H. Muntau, B. Griepink, and E.A. Maier. 1995. The certified reference materials CRM 142 R light sandy soil, CRM 143 R sewage sludge amended soil and CRM 145 R sewage sludge for quality control in monitoring environmental and soil pollution. Fresenius $\mathrm{Z}$. Anal. Chem. 352:197-202.

Voegelin, A., K. Barmettler, and R. Kretzschmar. 2003. Heavy metal release from contaminated soils: Comparison of column leaching and batch extraction results. J. Environ. Qual. 32:865-875.

Walkley, A., and A.I. Black. 1934. An examination of the Degtjareff method for determining soil organic matter, and a proposed modification of the chromic acid titration method. Soil Sci. 37:29-38. 